\title{
Front Matter: Volume 11193
}

, "Front Matter: Volume 11193," Proc. SPIE 11193, Nanophotonics and Micro/ Nano Optics V, 1119301 (19 December 2019); doi: 10.1117/12.2563690

SPIE. Event: SPIE/COS Photonics Asia, 2019, Hangzhou, China 


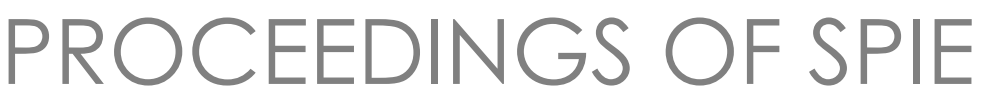

\title{
Nanophotonics and Micro/Nano Optics V
}

\author{
Zhiping Zhou \\ Kazumi Wada \\ Limin Tong \\ Editors
}

\section{1-23 October 2019 Hangzhou, China}

\author{
Sponsored by \\ SPIE \\ COS-Chinese Optical Society
}

\section{Cooperating Organizations}

Tsinghua University (China) • Peking University (China) • University of Science and Technology of China (China) • Zhejiang University (China) • Tianjin University (China) • Beijing Institute of Technology (China) • Beijing University of Posts and Telecommunications (China) - Nankai University (China) - Changchun University of Science and Technology (China) • University of Shanghai for Science and Technology (China) • Capital Normal University (China) - Huazhong University of Science and Technology (China) • Beijing Jiaotong University (China) • China Jiliang University (China) - Shanghai Institute of Optics and Fine Mechanics, CAS (China) - Changchun Institute of Optics, Fine Mechanics and Physics, CAS (China) - Institute of Semiconductors, CAS (China) - Institute of Optics and Electronics, CAS (China) - Institute of Physics, CAS (China) • Shanghai Institute of Technical Physics, CAS (China) • China Instrument and Control Society (China) - Japan Optical Society (Japan) - Korea Optical Society (Korea, Republic of) - Australia Optical Society (Australia) - Singapore Optical Society (Singapore) • European Optical Society

Supporting Organizations

China Association for Science and Technology (CAST) (China)

Department of Information of National Nature Science Foundation, China (NSFC) (China)

Published by

SPIE

Volume 11193 
The papers in this volume were part of the technical conference cited on the cover and title page. Papers were selected and subject to review by the editors and conference program committee. Some conference presentations may not be available for publication. Additional papers and presentation recordings may be available online in the SPIE Digital Library at SPIEDigitalLibrary.org.

The papers reflect the work and thoughts of the authors and are published herein as submitted. The publisher is not responsible for the validity of the information or for any outcomes resulting from reliance thereon.

Please use the following format to cite material from these proceedings:

Author(s), "Title of Paper," in Nanophotonics and Micro/Nano Optics V, edited by Zhiping Zhou, Kazumi Wada, Limin Tong, Proceedings of SPIE Vol. 11193 (SPIE, Bellingham, WA, 2019) Seven-digit Article CID Number.

ISSN: 0277-786X

ISSN: 1996-756X (electronic)

ISBN: 9781510631038

ISBN: 9781510631045 (electronic)

Published by

SPIE

P.O. Box 10, Bellingham, Washington 98227-0010 USA

Telephone +1 3606763290 (Pacific Time) · Fax +1 3606471445

SPIE.org

Copyright (c) 2019, Society of Photo-Optical Instrumentation Engineers.

Copying of material in this book for internal or personal use, or for the internal or personal use of specific clients, beyond the fair use provisions granted by the U.S. Copyright Law is authorized by SPIE subject to payment of copying fees. The Transactional Reporting Service base fee for this volume is $\$ 21.00$ per article (or portion thereof), which should be paid directly to the Copyright Clearance Center (CCC), 222 Rosewood Drive, Danvers, MA 01923. Payment may also be made electronically through CCC Online at copyright.com. Other copying for republication, resale, advertising or promotion, or any form of systematic or multiple reproduction of any material in this book is prohibited except with permission in writing from the publisher. The CCC fee code is 0277$786 \mathrm{X} / 19 / \$ 21.00$.

Printed in the United States of America by Curran Associates, Inc., under license from SPIE.

Publication of record for individual papers is online in the SPIE Digital Library.

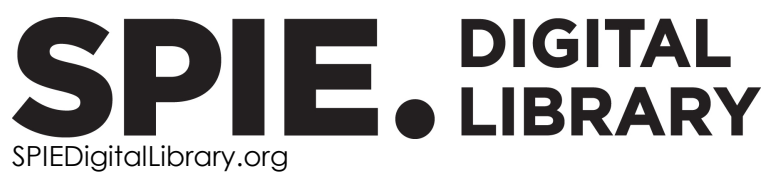

Paper Numbering: Proceedings of SPIE follow an e-First publication model. A unique citation identifier (CID) number is assigned to each article at the time of publication. Utilization of CIDs allows articles to be fully citable as soon as they are published online, and connects the same identifier to all online and print versions of the publication. SPIE uses a seven-digit CID article numbering system structured as follows:

- The first five digits correspond to the SPIE volume number.

- The last two digits indicate publication order within the volume using a Base 36 numbering system employing both numerals and letters. These two-number sets start with $00,01,02,03,04$, 05, 06, 07, 08, 09, OA, OB ... 0Z, followed by 10-1Z, 20-2Z, etc. The CID Number appears on each page of the manuscript. 


\title{
Contents
}

\author{
$\checkmark \quad$ Authors \\ vii Symposium Committees \\ xi Conference Committee
}

MICRO/NANO OPTOELECTRONIC INTEGRATION

1119309 Si-Ge intermixing induced at mesa sidewalls of Si-capped Ge epitaxial layers on Si for operation wavelength tuning in Ge photonic devices [1 11 193-7]

11193 OC Grating-assisted MDM-PDM hybrid (de)multiplexer for optical interconnect applications [11193-10]

OPTICAL MANIPULATION

$111930 Q \quad$ Reflection of whispering gallery modes propagating on the optical fiber surface from its facet [11193-26]

11193 OR Diffraction and interference of classical spiraling photons in accord with the law of conservation of energy [1 $11193-27]$

11193 OT Bandwidth optimization of germanium-doped silicon optical modulator for high-speed applications [1 11 193-28]

\section{NONLINEAR NANOPHOTONICS}

11193 OV Review of femtosecond laser induced surface periodic structure [1 11 193-32]

MICRO/NANO PHOTODETECTORS

$1119311 \quad$ All-inorganic halide perovskites thin-film self-powered photodetector [1 11 193-38]

\section{POSTER SESSION}

1119312 Wideband infrared metal wire grating polarizer using holographic lithography and lift-off process [1 $11193-25]$ 
1119313 Plasmon-enhanced fluorescence of nanoparticle-dye-protein complex as perspective approach for increase in fluorescent labeling effectiveness [1 11 193-39]

1119315 200-mm silicon photonics technology development [11193-41]

1119316 A comparative study of the spin-orbit interactions in Pancharatnam-Berry phase elements and in normal incidence of a light beam at a sharp interface [1 11 193-42]

1119318 Rutile $\mathrm{TiO}_{2}$ nanorod arrays grown by solution-processed for high efficiency solid state perovskite solar cells [ $111193-44]$

11193 1B Mode-locked fibre laser with e-controlled cavity length in ultra-wide range [ 111 193-48]

11193 1C Electronic-induced-transparency-like in a single polydimethysiloxane-coated whispering gallery mode microbubble resonator [1 $1193-49]$

11193 IE Novel hybrid adhesive material based on thiol-ene system for nano-conglutination technology [11193-51]

$1119311 \quad$ Raman lasing in optofluidic microbubble resonator [11193-55] 


\section{Authors}

Numbers in the index correspond to the last two digits of the seven-digit citation identifier (CID) article numbering system used in Proceedings of SPIE. The first five digits reflect the volume number. Base 36 numbering is employed for the last two digits and indicates the order of articles within the volume. Numbers start with 00, 01, 02, 03, 04, 05, 06, 07, 08, 09, 0A, 0B...0Z, followed by 10-1Z, 20-2Z, etc.

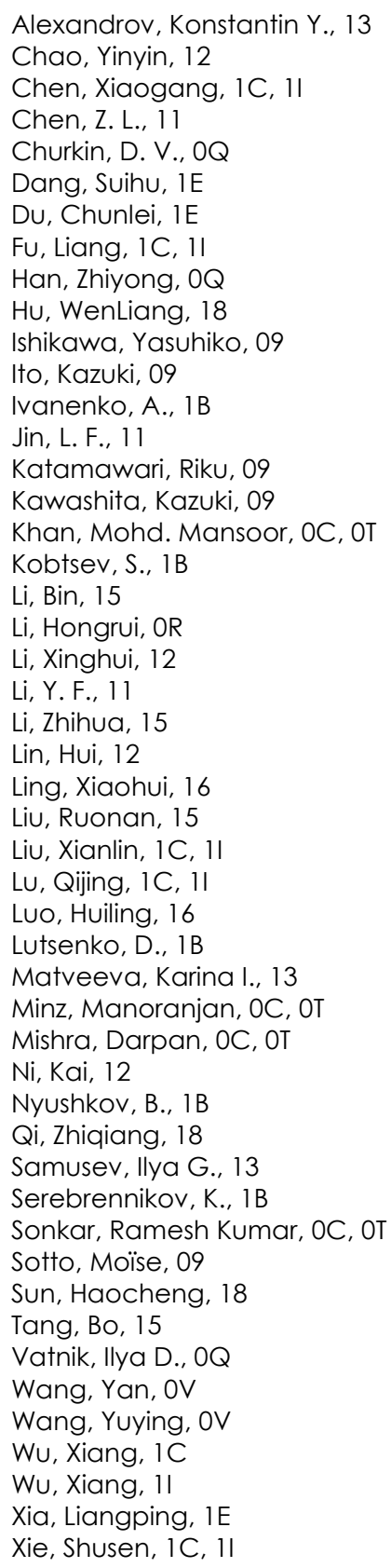

Yao, J. Q., 11

Yu, Y., 11

Zhang, Man, $1 \mathrm{E}$

Zhang, Peng, 15

Zhang, Y. T., 11

Zhdanov, Andrey, OV

Zhou, Qian, 12

Zhou, Xinxing, 16

Zyubin, Andrey Y., 13 
Proc. of SPIE Vol. $111931119301-6$

Downloaded From: https://www.spiedigitallibrary.org/conference-proceedings-of-spie on 26 Apr 2023 Terms of Use: https://www.spiedigitallibrary.org/terms-of-use 


\title{
Symposium Committees
}

\author{
General Chairs
}

Jim M. Oschmann, President, SPIE and Ball Aerospace (United States)

Qihuang Gong, President, Chinese Optical Society and Peking

University (China)

General Co-chairs

Guangcan Guo, Past President, Chinese Optical Society and University of Science and Technology of China (China)

Zejin Liu, Vice President, Chinese Optical Society and National University of Defense Technology (China)

Technical Program Chairs

Ruxin Li, Vice President, Chinese Optical Society and Shanghai Institute of Optics and Fine Mechanics (China)

Xingde Li, Johns Hopkins University (United States)

Technical Program Co-chairs

Tianchu Li, National Institute of Metrology (China)

Wei Huang, Northwestern Polytechnical University (China)

Ying Gu, Vice President, Chinese Optical Society and PLA General Hospital (China)

Huilin Jiang, Changchun University of Science and Technology (China)

Wenqing Liu, Vice President, Chinese Optical Society, and Anhui Institute of Optics and Fine Mechanics (China)

Guobin Fan, China Academy of Engineering Physics (China)

Suotang Jia, Vice President, Chinese Optical Society, and Shanxi University (China)

Xiaomin Ren, Vice President, Chinese Optical Society, and Beijing University of Posts and Telecommunications (China)

Secretaries-General

Bo Gu, Deputy Secretary General, Chinese Optical Society (China)

Hong Yang, Deputy Secretary General, Chinese Optical Society and Peking University (China) 
Yan Li, Deputy Secretary General, Chinese Optical Society, and Peking University (China)

Daoxin Dai, Zhejiang University (China)

Local Organizing Committee Chair

Xu Liu, Secretary General, Chinese Optical Society and Zhejiang University (China)

Local Organizing Committee Co-chairs

Jianrong Qiu, Zhejiang University (China)

Daoxin Dai, Zhejiang University (China)

Local Secretaries

Wei Xiong, Chinese Optical Society (China)

Qing Yang, Zhejiang University (China)

Local Organizing Committee

Qing Yang, Zhejiang University (China)

Lan Wu, Zhejiang University (China)

Yaocheng Shi, Zhejiang University (China)

Dong Liu, Zhejiang University (China)

Yungui Ma, Zhejiang University (China)

Ke Si, Zhejiang University (China)

Yang Yang, Zhejiang University (China)

Xinyong Dong, China Jiliang University (China)

Le Wang, China Jiliang University (China)

Fei Tong, Chinese Optical Society (China)

Technical Organizing Committee

Mohammad Hossein Asghari, Loyola Marymount University

(United States) and Tachyonics Inc. (United States)

Pablo Benítez, Universidad Politécnica de Madrid (Spain)

Liangcai Cao, Tsinghua University (China)

P. Scott Carney, University of Rochester (United States)

Benyong Chen, Zhejiang University of Science and Technology

(China)

Hongqiang Chen, GE Global Research (United States)

Daoxin Dai, Zhejiang University (China)

Qionghai Dai, Tsinghua University (China)

Qihuang Gong, Peking University (China)

Ying Gu, Chinese PLA General Hospital (China) 
Guang-Can Guo, University of Science and Technology of China (China)

Byoung Seung Ham, Gwangju Institute of Science and Technology (Korea, Republic of)

Sen Han, University of Shanghai for Science and Technology (China) and Suzhou H\&L Instruments, LLC (China)

Zuyuan He, Shanghai Jiao Tong University (China)

Werner H. Hofmann, Technische Universität Berlin (Germany)

Minghui Hong, National University of Singapore (Singapore)

Bahram Jalali, University of California, Los Angeles (United States)

Satoshi Kawata, Osaka University (Japan)

Baojun Li, Jinan University (China)

Ming Li, Institute of Semiconductors, CAS (China)

Ruxin Li, Shanghai Institute of Optics and Fine Mechanics (China)

Xingde Li, Johns Hopkins University (United States)

Jian Liu, PolarOnyx, Inc. (United States)

Tiegen Liu, Tianjin University (China)

Yongfeng Lu, University of Nebraska-Lincoln (United States)

Qingming Luo, Huazhong University of Science and Technology

(China)

Gang-Ding Peng, The University of New South Wales (Australia)

Osamu Matoba, Kobe University (Japan)

Min Qiu, Westlake University (China)

Yuji Sano, ImPACT (Japan)

Yunlong Sheng, Université Laval (Canada)

Kebin Shi, Peking University (China)

Tsutomu Shimura, The University of Tokyo (Japan)

Upendra N. Singh, NASA Langley Research Center (United States)

Michael G. Somekh, Shenzhen University (China)

Yuguo Tang, Suzhou Institute of Biomedical Engineering and

Technology (China)

Masahiko Tani, University of Fukui (Japan)

Limin Tong, Zhejiang University (China)

Kazumi Wada, Massachusetts Institute of Technology (United States)

Yongtian Wang, Beijing Institute of Technology (China)

Rongshi Xiao, Beijing University of Technology (China)

Hongxing $X u$, Wuhan University (China)

Jianhua Yao, Zhejiang University of Technology (China)

Toru Yoshizawa, Tokyo University of Agriculture and Technology (Japan) and 3D Associates, Inc. (Japan)

Changyuan Yu, The Hong Kong Polytechnic University

(Hong Kong, China)

Xiao-Cong Yuan, Shenzhen University (China)

Cunlin Zhang, Capital Normal University (China)

Song Zhang, Purdue University (United States)

Xi-Cheng Zhang, University of Rochester (United States) 
Xinliang Zhang, Wuhan National Laboratory for Optoelectronics (China)

Xuping Zhang, Nanjing University (China)

Zhenrong Zheng, Zhejiang University (China)

Changhe Zhou, Shanghai Institute of Optics and Fine Mechanics (China)

Zhiping Zhou, Peking University (China)

Dan Zhu, Huazhong University of Science and Technology (China)

Ning Hua Zhu, Institute of Semiconductors, CAS (China) 


\title{
Conference Committee
}

\author{
Symposium Chairs
}

Jacobus M. Oschmann, Ball Aerospace (United States)

Qihuang Gong, Peking University (China)

Conference Chairs

Zhiping Zhou, Peking University (China)

Kazumi Wada, Massachusetts Institute of Technology (United States)

Limin Tong, Zhejiang University (China)

Conference Program Committee

Eric Cassan, Centre de Nanosciences et de Nanotechnologies

(France)

Tao Chu, Zhejiang University (China)

David S. Citrin, Georgia Institute of Technology (United States)

Hiroshi Fukuda, NTT Device Technology Laboratories (Japan)

Min Gu, RMIT University (Australia)

El-Hang Lee, INHA University (Korea, Republic of)

Ching-Fuh Lin, National Taiwan University (Taiwan, China)

Gong-Ru Lin, National Taiwan University (Taiwan, China)

Yan-Qing Lu, Nanjing University (China)

Jurgen Michel, Massachusetts Institute of Technology (United States)

Takahiro Nakamura, Photonics Electronics Technology Research Association (PETRA) (Japan)

Andrew W. Poon, Hong Kong University of Science and Technology (Hong Kong, China)

Haisheng Rong, Intel Corporation (United States)

Yikai Su, Shanghai Jiao Tong University (China)

Hon Ki Tsang, The Chinese University of Hong Kong (Hong Kong, China)

Yun-Feng Xiao, Peking University (China)

Dan-Xia Xu, National Research Council Canada (Canada)

Koji Yamada, National Institute of Advanced Industrial Science and Technology (Japan)

Qing Yang V, Zhejiang University (China)

Changhe Zhou, Jinan University (China)

Weidong Zhou, The University of Texas at Arlington (United States) 


\section{Session Chairs}

1 Micro/Nano Light Emitting Devices

Qing Yang, Zhejiang University (China)

Xin Guo, Zhejiang University (China)

2 Micro/Nano Optoelectronic Integration

Eric Cassan, Centre de Nanosciences et de Nanotechnologies (France)

Tawfique Hasan, University of Cambridge (United Kingdom)

3 Nanobiophotonics Sensors

Chen Yang, Boston University (United States)

4 Nanostructures and Nanomaterials

Yang Yang, Zhejiang University (China)

Qinghai Song, Harbin Institute of Technology (China)

5 Optical Manipulation

Xiaoshun Jiang, Nanjing University (China)

Wei Fang, Zhejiang University (China)

6 Nonlinear Nanophotonics

Yong Zhang, Nanjing University (China)

7 Micro/Nano Photodetectors

Yaoguang Ma, Zhejiang University (China) 